\title{
Inclusão de alunos com Necessidades Educativas Especiais: o olhar de diferentes
}

\author{
atores
}

\section{Inclusion of students with special educational needs: perspectives from different actors}

\author{
Raquel Batista de Oliveira, Maria da Graça Amaro Bidarra, Maria Piedade Vaz-Rebelo \\ FPCE da Universidade de Coimbra
}

\begin{abstract}
Resumo
O presente estudo tem como objetivo conhecer as perceções dos diferentes atores sobre as práticas inclusivas de alunos com Necessidades Educativas Especiais nas escolas portuguesas. Neste sentido, recorreu-se à entrevista semiestruturada direcionada para professores da Educação Especial e professores do Ensino Regular. Para a análise dos dados utilizou-se a técnica análise de conteúdo. Os resultados revelam que apesar de existir alguma convergência nas respostas, emergem diferentes perceções destes docentes quanto à necessidade de recursos humanos e materiais, bem como ao seu reconhecimento no funcionamento da escola.

Palavras-chaves: Necessidades Educativas Especiais; Avaliação Externa de Escolas; Diferenciação e Apoios.
\end{abstract}

\begin{abstract}
The present study aims at recognizing the perception of different actors regarding the inclusion practices related to students with special educational needs in Portuguese schools. Thus, semi-structured interviews were done with special education and regular teachers. Content analysis then proceeded to evaluate the acquired data. Results reveal that despite some convergence in the gathered answers, different perceptions are found among the teaching body regarding the need for human resources and material resources, as well as its recognition in the school operation. Keywords: Special Needs Education; External School Assessment. Pedagogical Differentiation. Educaional Support.
\end{abstract}

A proposta da Educação "Para Todos" defendida pela Declaração de Salamanca, de 20 de Dezembro de 1994, sustenta que toda pessoa tenha o direito a uma educação de qualidade. Neste propósito, mediante a construção de uma educação de qualidade para todos, a inclusão de alunos com Necessidades Educativas Especiais sustenta-se sob uma perspetiva de dá condições para que estes alunos adquiram competências cognitivas e sociais. Desse modo, em Portugal a inclusão de alunos com Necessidade Educativas Especiais é regida pelo Decreto Lei 3/2008, onde propõe o enquadramento do grupo-alvo da educação especial, “[...] bem como as medidas organizativas, de funcionamento, de avaliação e de apoio" (Capucha, 2008, p.17). Para tanto, a avaliação da qualidade da educação nas instituições de ensino não superior é levada a cabo por um Programa Nacional de Avaliação Externa de Escolas (AEE) em Portugal, coordenado pela Inspeção Geral de Educação e Ciência.

Sobre isto, no primeiro ciclo avaliativo da AEE (2006-2011), face ao domínio Prestação do Serviço Educativo, o fator Diferenciação $e$ apoios obteve classificações entre Muito Bom e Bom em maior percentagem, constando igualmente entre os pontos fortes, com maior frequência do que entre os pontos fracos das escolas (Inspeção Geral de Educação, 2006-2011). No entanto, no segundo ciclo avaliativo da AEE (2011-2012), este fator desaparece e surge como referente nos campos de análise Planeamento $e$ avaliação, Práticas de ensino e Monitorização $e$ avaliação do ensino e das aprendizagens (Bidarra, Barreira, Vaz-Rebelo e Alferes, 2014). A partir disto, surgiu o interesse em mapear estas práticas com o propósito de perceber qual escolas desenvolvem boas práticas inclusivas e seguidamente tentar conhecer as perceções dos professores de Ensino Regular e de Educação Especial, Equipa Técnico pedagógica e Encarregados da Educação relativamente às dificuldades e desafios da prática educativa desenvolvidas nestas escolas, perceção face o Decreto lei 3/2008, práticas de colaboração desenvolvidas na escola, medidas de diferenciação e apoio, necessidades de recursos humanos, necessidades de recursos materiais, estrutura do espaço escolar para alunos com NEE. Dentre essas categorias a seguir apresentamos duas as quais escolhemos para compor este estudo bem como os participantes que integram o mesmo.

\section{Método}

Este estudo teve como participantes seis professores da Educação Especial, quatro professores do Ensino Regular referentes a três escolas Zona Centro de Portugal Continental. Para recolha de dados, utilizamos entrevista semiestruturada destinada a estes participantes. Para análise dos dados recorremos a técnica da análise de conteúdo das respostas, desenvolvendo um sistema de 
categorização que incluiu entre as várias categorias a que se refere às necessidades de recursos humanos destinados a escola e necessidades de recursos materiais destinados à escola.

\section{Resultados}

No que remete as categorias construídas, optamos para compor este estudo às categorias intituladas Necessidade de recursos humanos destinados à escola (Quadro 1, Quadro 2, Quadro 3, Quadro 4, Quadro 5) e Necessidade de resursos materiais destinados à escola (Quadro6, Quadro 7, Quadro 8, Quadro 9) com suas respetivas subcategorias, respetivos indicadores e frequência dos mesmos. Para tanto, foram identificadas a perceções dos Docentes do Ensino Especial e da Educação Regular.

Referente as perceções dos docentes do Ensino Regular e da Educação Especial (Quadro, 1, Quadro 2, Quadro 3) face à categoria Necessidade de recursos humanos destinados à escola foram identificadas subcategorias como Tipos de recursos humanos destinados à escola, impacto da falta de recursos humanos, recursos humanos disponíveis, iniciativa da escola face ás necessidades de recursos humanos, dificuldades e instituições que disponibilizam recursos humanos.

Quadro 1.

Frequência dos indicadores referente à subcategoria Al. Tipos de recursos humanos necessários da categoria ANecessidades em Recursos humanos nos docentes de Educação Especial (DocEE) e nos docentes do Ensino Regular (DocER)

\begin{tabular}{llc}
\hline \multicolumn{1}{c}{ Indicador } & DocEE & DocER \\
\hline A1.1Professores da Educação & 2 & 2 \\
Especial & & \\
A1.2 Professores no âmbito geral & 3 & 1 \\
A1.3 Funcionários para atender os & & \\
alunos com NEE & 1 & 2 \\
A1.4 Uma assistente social & 2 & \\
A1.5 Uma Terapeuta Ocupacional & \\
A1.6 Uma psicometrista em & 2 & 1 \\
tempo integral & & \\
A1.7 Mais um psicólogo para o & & \\
atendimento aos alunos com NEE & 2 & 6 \\
Total & 12 & \\
\hline
\end{tabular}

No que se refere ao quadro acima (cf. Quadro 1) verificamos que as maiores frequências estão elencadas nas subcategorias com seus respetivos indicadores em destaque: A1. Tipos de recursos humanos necessários com seus indicadores, A1.1 Professores da Educação Especial, A1.2 professores no âmbito geral, A1.3 Funcionários para atender os alunos com NEE, A1.5 uma terapeuta ocupacional, A1.6 Mais um psicólogo para o atendimento aos alunos com NEE, A1.7 Uma psicometrista em tempo integral. Refere-se ainda que há convergências nas respostas dos docentes da Educação Especial e dos Docentes do Ensino Regular no que concerne os indicadores de ambas subcategorias: A1.1 Professores da Educação Especial A1.2 Professores no âmbito geral, A1.6 Mais um psicólogo para o atendimento aos alunos com NEE, sendo que há mais frequências nas respostas dos docentes da Educação
Especial que nos docentes do ensino regular relativamente aos indicadores das subcategorias em destaque.

Quadro 2.

Frequência dos indicadores referente à subcategoria Impacto da falta de recursos humanos da categoria ANecessidades em Recursos humanos nos docentes de Educação Especial (DocEE) e nos docentes do Ensino Regular (DocER)

\begin{tabular}{|c|c|c|}
\hline Indicador & DocEE & DocER \\
\hline $\begin{array}{l}\text { A2.1 A ausência de recursos } \\
\text { afeta o tempo destinado ao } \\
\text { atendimento dos alunos com } \\
\text { NEE }\end{array}$ & 4 & 2 \\
\hline $\begin{array}{l}\text { A2.2 A falta de recursos } \\
\text { humanos afeta a disponibilidade } \\
\text { de apoios individualizados para } \\
\text { os alunos com NEE }\end{array}$ & 1 & \\
\hline $\begin{array}{l}\text { A2.3 Não há serviços da } \\
\text { psicologia próprios da escola }\end{array}$ & 4 & \\
\hline $\begin{array}{l}\text { A2.4 Falta de apoio } \mathrm{e} \\
\text { comprometimento } \\
\text { atendimento dos alunos } \\
\text { NEE }\end{array}$ & 1 & 3 \\
\hline $\begin{array}{l}\text { A2.5 Discrepância entre o que } \\
\text { está estipulado na Lei e } \\
\text { Orientações e o que se consegue } \\
\text { fazer (na prática) }\end{array}$ & 1 & \\
\hline Total & 11 & 5 \\
\hline
\end{tabular}

Face ao quadro acima (cf. Quadro 2) verificamos que as maiores frequências estão presentes nas subcategorias com seus respetivos indicadores em destaque: A2. Impacto da falta de recursos humanos com seus indicadores A2.1 A ausência de recursos afeta o tempo destinado ao atendimento dos alunos com NEE, A2.3 Falta de apoio e comprometimento do atendimento dos alunos com NEE. É de referir ainda que há convergências nas respostas dos docentes do ensino regular e da educação espacial no que concerne aos indicadores A2.1 A ausência de recursos afeta o tempo destinado ao atendimento dos alunos com NEE, A2.3 Falta de apoio e comprometimento do atendimento dos alunos com NEE, ainda, há mais frequências nas respostas dos docentes da Educação Especial que nos docentes do ensino regular relativamente aos indicadores das subcategorias em destaque.

Quadro 3.

Frequência dos indicadores referente à subcategoria A3. Recursos humanos disponíveis da categoria $A$ Necessidades em Recursos humanos nos docentes de Educação Especial (DocEE) e nos docentes do Ensino Regular (DocER)

\begin{tabular}{lll}
\hline \multicolumn{2}{c}{ Indicador DocEE } & DocER \\
\hline A3.1 Há técnicos suficientes & 1 & \\
A3.2 Há terapeutas da fala & 1 & \\
A3.3 Há psicólogos & 1 & \\
disponíveis no agrupamento & & \\
de escolas & & \\
A3.4 Há uma terapeuta & 1 & 0 \\
ocupacional na escola & 4 & \\
Total
\end{tabular}


Conforme o quadro acima (cf. Quadro 3) verificamos que não houve frequências elevadas relativamente aos tipos de recursos humanos presentes na escola, assim como não houve referências nas respostas dos docentes do Ensino Regular relativamente a esta subcategoria, sendo assim, não houve convergências nas respostas dos docentes da Educação Especial e do Ensino Regular face à esta subcategoria com seus respetivos indicadores.

Quadro 4.

Frequência dos indicadores referente à subcategoria A4. Iniciativas da escola face às necessidades de recursos Humanos da categoria Al- Necessidades em Recursos humanos nos docentes de Educação Especial (DocEE) $e$ nos docentes do Ensino Regular (DocER)

\begin{tabular}{lll}
\hline Indicador & \multicolumn{1}{c}{ DocEE } & DocER \\
\hline A4.1 A escola solicita técnicos mas & 3 & 1 \\
não há retorno & 1 \\
A4.2 A escola solicita técnicos mas & \\
só é destinado um número reduzido & \\
A4.3 A escola não tem solicitado & 1 \\
técnicos para o atendimento dos & \\
alunos com NEE & \\
A4.4 A escola solicita sempre & 3 & \\
técnicos & & \\
A4.5 A escola solicita às vezes & 1 & \\
técnicos & \\
Total & 7 & 3 \\
\hline
\end{tabular}

O quadro acima (cf. Quadro 4) podemos afirmar que as frequências mais elevadas estão nos indicadores A4.1 A escola solicita os técnicos, mas não há retorno e A4.4 A escola solicita sempre os técnicos. É de referir ainda que há convergências nas respostas dos docentes da Educação Especial e do Ensino Regular no que se refere a estes mesmos indicadores. Ainda, destacam-se os indicadores com mais frequências nas respostas dos docentes da Educação Especial que dos docentes do Ensino Regular.

\section{Quadro 5.}

Frequência dos indicadores referente à subcategoria A5. Dificuldades e A6. Instituições que disponibilizam recursos Humanos da categoria A-Necessidades em Recursos humanos nos docentes de Educação Especial (DocEE) e nos docentes do Ensino Regular (DocER)

\begin{tabular}{lcc}
\hline \multicolumn{1}{c}{ Indicador } & DocEE & DocER \\
\hline A5.1Tempo envolvido no & 1 & \\
encaminhamento de docentes & & \\
substitutos a partir da & \\
solicitação destes & & \\
A6.1 O CRI disponibiliza & & \\
terapeutas da fala para a & 1 & 0 \\
escola & 2 & \\
Total & & \\
\hline
\end{tabular}

Relativamente ao quadro acima (cf. Quadro 5) verificamos que não há frequências elevadas nos indicadores da subcategoria referida, registando-se também ausência da frequência nas respostas dos docentes do Ensino regular, não havendo nenhuma convergência nas respostas dos mesmos junto aos docentes da Educação Especial.

Quadro 6.

Frequência dos indicadores referente à subcategoria $B 1$. Impacto das falta dos recursos materiais da categoria $B$ Necessidades em Recursos materiais destinados à escola nos docentes de Educação Especial (DocEE) e nos docentes do Ensino Regular (DocER)

\begin{tabular}{|c|c|c|}
\hline Indicador & DocEE & DocER \\
\hline $\begin{array}{l}\text { B1.1Os recursos materiais } \\
\text { não são suficientes }\end{array}$ & 3 & 2 \\
\hline $\begin{array}{l}\text { B1.2Dificuldade sentidas } \\
\text { por parte dos docentes no } \\
\text { ensino pela razão da } \\
\text { ausência de tecnologias de } \\
\text { apoio }\end{array}$ & 1 & 1 \\
\hline $\begin{array}{l}\text { B1.3Pela insuficiência de } \\
\text { materiais didáticos os } \\
\text { docentes constroem os } \\
\text { materiais didáticos para } \\
\text { integrarem o ensino junto } \\
\text { aos alunos com NEE }\end{array}$ & 2 & \\
\hline $\begin{array}{l}\text { B1.4Não há nenhum } \\
\text { recurso material para } \\
\text { atender os alunos com NEE }\end{array}$ & 1 & 1 \\
\hline $\begin{array}{l}\text { B1.5A insuficiência de } \\
\text { materiais didáticos } \\
\text { compromete a qualidade do } \\
\text { ensino junto aos alunos com } \\
\text { NEE }\end{array}$ & 1 & \\
\hline Total & 9 & 4 \\
\hline
\end{tabular}

Conforme o quadro acima (cf. Quadro 6) verifica-se que as frequências maiores estão presentes no indicador B1. Perceção face às necessidades em recursos materiais com seus indicadores B1.1 Os recursos materiais não são suficientes, B1.3 Pela insuficiência de materiais didáticos os docentes constroem os materiais didáticos para integrarem o ensino junto aos alunos com NEE. È de referir também que há convergências nas respostas dos docentes da Educação Especial e dos Docentes do Ensino Regular no que concerne aos indicadores B1.1 Os recursos materiais não são suficientes, B1.2 Dificuldade sentidas por parte dos docentes no ensino pela razão da ausência de tecnologias de apoio, B1.4 Não há nenhum recurso material para atender os alunos com NEE, sendo que há mais frequências nas respostas dos docentes da Educação Especial que nos dos docentes do Ensino Regular. 
Quadro 7.

Frequência dos indicadores referente à subcategoria B2. Recursos materiais disponíveis B-Necessidades em Recursos materiais destinados à escola nos docentes de Educação Especial (DocEE) e nos docentes do Ensino Regular (DocER)

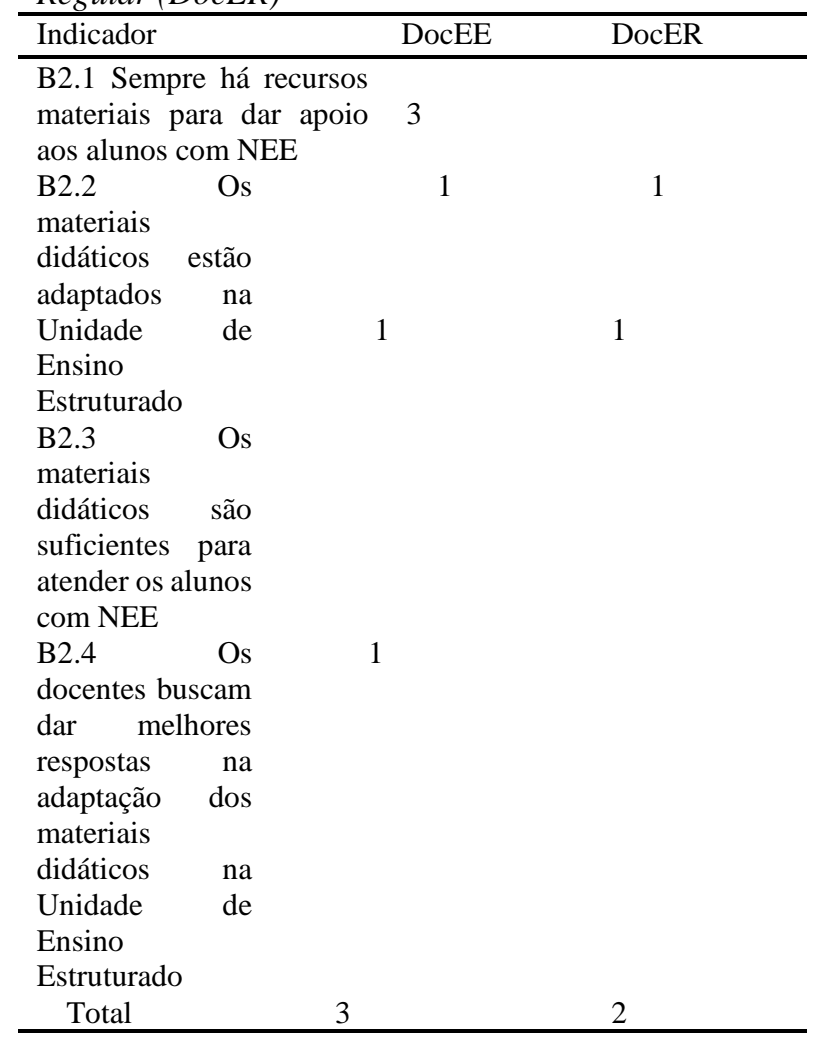

No quadro acima (cf. Quadro 7) verificamos que as maiores frequências estão presentes na subcategoria com seus respetivos indicadores em destaque: B2. Perceção face a presença dos recursos materiais na escola, com seu indicador B2.1 Sempre há recursos materiais para dá apoio aos alunos com NEE. Há convergências nas respostas dos docentes da Educação Especial e dos Docentes do Ensino Regular no que concerne aos indicadores B2.2 Os materiais didáticos estão adaptados na Unidade de Ensino Estruturado e B2.3 Os materiais didáticos são suficientes para atender os alunos com NEE, sendo que há mais frequência dos indicadores nas respostas dos docentes da Educação Especial.
Quadro 8.

Frequência dos indicadores referente à subcategoria B3 Tipos de recursos materiais necessários da categoria $B$ Necessidades em Recursos materiais destinados à escola nos docentes de Educação Especial (DocEE) e nos docentes do Ensino Regular (DocER)

\begin{tabular}{lll}
\hline \multicolumn{1}{c}{ Indicador DocEE } & DocER \\
\hline & & 2 \\
B3.1 Necessidade de mais & 3 & \\
computadores e materiais & & \\
interativos para atender os & \\
alunos com NEE & & \\
B3.2 Necessidade de & 2 & 1 \\
Jogos didáticos e filmes \\
Materiais que captem a \\
atenção do aluno \\
$\begin{array}{l}\text { B3.3 Necessidade de } \\
\text { transporte para o }\end{array}$ \\
acompanhamento aos \\
alunos com NEE junto as \\
atividades extraescolar \\
B3.4 Necessidade de \\
baterias de testes \\
B3.5 Necessidade de um \\
espaço polivalente para \\
contribuir na \\
aprendizagem/socializaçã \\
o dos alunos com NEE \\
Total
\end{tabular}

No quadro acima (cf. Quadro 8) percebemos que as maiores frequências estão elencadas na subcategoria com seus respetivos indicadores em destaque: B3.1 Necessidade de mais computadores e materiais interativos para atender os alunos com NEE, B3.2 Necessidade de Jogos didáticos e filmes. Há convergências nas respostas dos docentes da Educação Especial e dos Docentes do Ensino Regular no que concerne aos indicadores: B3.1 Necessidade de mais computadores e materiais interativos para atender os alunos com NEE, B3.2 Necessidade de Jogos didáticos e filmes, B3.6 Necessidade de um espaço polivalente para contribuir na aprendizagem/socialização dos alunos com NEE. É de referir ainda que há mais frequências dos indicadores nas respostas dos docentes da Educação Especial.

Quadro 9.

Frequência dos indicadores referente à subcategoria B4 Adaptação dos recursos materiais da categoria $B$ Necessidades em Recursos materiais destinados à escola nos docentes de Educação Especial (DocEE) e nos docentes do Ensino Regular (DocER)

\begin{tabular}{lll}
\hline Indicado & DocEE & DocER \\
\hline B4.1 A adaptação das & 1 & \\
tecnologias de apoio para o & & \\
aluno depende da & & \\
solicitação por parte da & \\
escola & & \\
B4.2 Há tecnologias de & 1 & \\
apoio para os alunos com & & \\
NEE & 1 & 0 \\
B4.3 Os computadores não & 1 & \\
são adaptados para atender & & \\
os alunos com NEE & 3 & \\
Total
\end{tabular}

No que concerne o quadro acima (cf. Quadro 9) verificamos que não há frequências elevadas nos 
indicadores face as respostas dos docentes da Educação Especial e Ensino Regular. É de referir ainda que não há nenhuma convergência nas respostas dos docentes da Educação Especial junto aos docentes do Ensino Regular, não havendo também nenhuma frequência no que se refere as respostas dos docentes do Ensino regular.

\section{Discussão}

Pelo exposto, regista-se alguma convergência nas repostas dos docentes de Educação Especial e do Ensino Regular no reconhecimento de que existem necessidades de recursos humanos e materiais destinados a alunos com NEE. No entanto, são os docentes de Educação Especial mais do que os docentes de Ensino Regular que apontam a falta de recursos humanos, tais como docentes de Educação Especial , docentes em geral, terapeutas ocupacionais e psicólogo. Por sua vez, os docentes de Ensino Regular não dão conta dos recursos disponíveis na escola. São igualmente os docentes de Educação Especial que apontam com mais frequência a necessidade de recursos como tecnologias de apoio e jogos interativos que auxiliam na condução do processo de ensino e aprendizagem junto dos alunos com NEE.

Estes dados revelam que existem algumas diferenças nas perceções por parte dos docentes de Ensino Especial e de Ensino Regular, não existindo uma visão partilhada no que se refere a algumas necessidades e presenças dos recursos humanos e materias. A existência dessa visão partilhada remete para uma cultura de colaboração onde todos os atores que integram o espaço escolar estejam cientes das necessidades e da presença destes recursos que influenciam diretamente a qualidade da prática com os alunos com NEE.

\section{Referências}

Bidarra, M G, Barreira, C. M., Vaz-Rebelo, M. P., \& Alferes, V., (2014). Avaliação externa de escolas: Da análise das redundâncias à ponderação diferencial dos resultados no primeiro ciclo de avaliação In $J$. A. Pacheco (Ed.) Avaliação Externa de Escolas (pp. 229-246). Porto: Porto Editora.

Capucha, L., (2008). Educação Especial. Manual de Apoio à Prática. Lisboa

Decreto-Lei No 3/2008. Diário da República - I Série $N^{o} 4$ de 7 de Janeiro. Define a atuação dos apoios educativos, adequação do processo educativo às necessidades educativas especiais, finalidades da inclusão de pessoas com NEE.

Inspeção Geral da Educação (2006-2011). Avaliação Externa das Escolas: avaliar para a melhoria $e$ confiança. Ministério da Educação - IGE.

\section{Agradecimentos}

Doutoramento financiado pela Coordenação de Apoio ao Pessoal de Nível Superior (CAPES). 